\title{
Stigma and Discrimination against People Living with HIV and AIDS in Malawi
}

\author{
Mercy Pindani' ${ }^{1}$ Makhubela Nkondo ${ }^{2}$, Alfred Maluwa ${ }^{1 *}$, Sadandaula Muheriwa ${ }^{1}$ \\ ${ }^{1}$ Kamuzu College of Nursing, University of Malawi, Lilongwe Campus, Lilongwe, Malawi \\ ${ }^{2}$ University of South Africa, Pretoria, South Africa \\ Email:mercypindani@kcn.unima.mw, makhaon@unisa.ac.za, ${ }^{*}$ aomaluwa@kcn.unima.mw, \\ rmuheriwa@kcn.unima.mw
}

Received 3 March 2014; revised 3 April 2014; accepted 13 April 2014

Copyright (C) 2014 by authors and Scientific Research Publishing Inc.

This work is licensed under the Creative Commons Attribution International License (CC BY).

http://creativecommons.org/licenses/by/4.0/

c) (i) Open Access

\section{Abstract}

A study was conducted to explore stigma and discrimination among people living with HIV and AIDS who were on home based care in the Lilongwe district of Malawi. The study design was descriptive through sectional and utilized qualitative data collection and analysis method. Fifteen people living with HIV and AIDS, aged between 15 and 60 years were purposively sampled from three organizations, which were: Light House, National Association for people living with HIV and AIDS in Malawi and Lilongwe Diocese. Qualitative data were collected using an open ended interview guide during in-depth face to face interviews with the participants. The data were analysed using ATLAS. ti 5.0. Results show that all the participants were facing stigma and discrimination because they were living with HIV and AIDS. Distant relatives were the main source of stigma and discrimination followed by friends and church members. Most participants indicated that they felt they were discriminated because HIV infection is associated with bad behaviours such as prostitution or promiscuity. However some of them complained that they contracted the virus from their married partners and hence they did not deserve to be stigmatized or discriminated against. Results show that there is a need for creation of awareness among community members on the transmission of HIV and the need for home based care for the chronically ill people living with HIV and AIDS.

\section{Keywords}

People Living with HIV and AIDS, Community Home Based Care, Stigma and Discrimination, Primary Care Providers, HIV Transmission and Prevention

\footnotetext{
${ }^{*}$ Corresponding author.
} 


\section{Introduction}

Globally, 33 million people are living with HIV of which 30.8 million are adults and 2.2 million are children [1]. The worst affected region is sub-Saharan Africa, with 22 million people (adults and children) living with HIV and AIDS. For example in 2008, women accounted for 50\% of all adults living with HIV worldwide of which $59 \%$ were in sub-Saharan Africa [1]. In Malawi, the adult prevalence rate of HIV is at $10.6 \%$ [2]. Currently, about one million people, including children under the age of 15, are living with HIV and AIDS of which women constitute $60 \%$ [1].

An effective and affordable community home based care (CHBC) for people living with HIV and AIDS (PLWHA) has potential to positively impact the health and social status of patients, families and the community as a whole. The introduction of life prolonging drugs such as ARVs has made HIV and AIDS be one of the chronicle illnesses. Due to limited bed space in most public hospitals, many chronically ill patients go home upon discharge from a health facility while continuous care is still required. For this reason in Malawi, CHBC for chronically ill patients is one of the interventions that were recommended for the care of PLWHA [4] [5]. In CHBC, the family has always been and still remains the major provider of long term care for patients including PLWHA. CHBC is therefore the best way for most people to be cared for and to die peacefully [3]. Other positive effects of CHBC are that it raises awareness among community members about HIV and AIDS and reduces stigma thus preventing the spread of HIV and gets rid of myths and misconceptions about HIV and AIDS [3]. CHBC also helps communities understand issues of HIV and AIDS and makes it easier to provide support by tapping all possible community resources and helping to bring the community together to combat HIV and AIDS and advocate for more services [3]. However, HIV and AIDS infected members of the family can find themselves facing a lot of challenges including stigma and discrimination within the home [6].

Stigma remains the single most important barrier to public action [6]. AIDS related stigma refers to the prejudice and discrimination directed at people living with HIV and AIDS and the groups and communities that they are associated with. It causes people living with HIV and AIDS to be rejected from their community, shunned, discriminated against or even get physically hurt [7]. Research evidence shows that some HIV and AIDS patients face some kind of stigma and discrimination [7]. Stigma when directed at PLWHA complicates the fight against HIV and AIDS because when stigmatized the PLWHA have difficulties to cope with the illness at a personal level [7]. In addition, stigma also interferes with attempts to fight the AIDS epidemic as a whole. Studies on the lived experiences of PLWHA regarding stigma and discrimination are scarce in Malawi. Therefore, the aim of this study was to describe the lived experiences of HIV and AIDS patients who were on CHBC Programme regarding stigma and discrimination in the Lilongwe district of Malawi.

\section{Methodology}

The study design was descriptive and utilized qualitative phenomenological approach to data collection and analysis to provide comprehensive description of the experiences of PLWHA regarding their experiences with stigma and discrimination [8]. A total of 15 PLWHA were purposefully sampled and interviewed to provide in-depth information regarding their experiences with stigma and discrimination. The participants were chosen from 3 major organizations dealing with PLWHA in Lilongwe district. The organizations were: Light House which is a public/government institution, National Association for People Living with HIV and AIDS in Malawi, (NAPHAM), and the Lilongwe Diocese, a faith based organization. The interviews were audio-taped, transcribed verbatim and analyzed qualitatively using ATLAS. ti version 5 [9].

\section{Inclusion and Exclusion Criteria}

Participants who were recruited in the study were at least 14 years, living with HIV and AIDS in Lilongwe district and were enrolled into a community home based care program for not less than 6 months. PLWHA who were below 14 years or residing in other districts other than Lilongwe or those residing in Lilongwe but not enrolled in CHBC were excluded from the study.

\section{Ethical Issues}

The study was approved by the Research and Ethics Committee of the University of South Africa (UNISA) and the University of Malawi, College of Medicine Research and Ethics Committee (COMREC). To access the par- 
ticipants, the researcher obtained permission from the heads of Light House, NAPHAM and Lilongwe Diocese. Participation was voluntary and participants were informed that they could withdraw from the study at any time if they wished. Informed consent was obtained from each participant who met the inclusion criteria including the minors where accent was obtained from their parents or guardians before being interviewed. The participants were allocated code numbers instead of names to ensure confidentiality and anonymity.

\section{Data Collection}

A total of 15 in-depth face to face interviews were conducted by the senior author who was then a Ph.D. student and was assisted with two trained research assistants who were also state registered nurses. The participants were identified by nurses who were working in the three CHBC institutions in Lilongwe. Researchers confirmed that participants met the inclusion criteria and consented to the study. Interviews were conducted at a private place within the PLWHA's homes. Each interview was audio taped and field notes were manually taken. During the interviews, demographic data which included age, sex, marital status, occupation, religion and level of education were collected. An open ended interview guide was used to seek in-depth information on stigma and discrimination. Probes were made to understand the participants' responses and comments regarding stigma and discrimination. Concentration was placed on the theme of the study which was participants' perception of being stigmatized and discriminated. Specifically, information was collected regarding perception of the participants on who stigmatized them, reasons for being stigmatized and signs that indicated stigma and discrimination. Finally, participants were also asked whether the people who stigmatized them had received HIV and AIDS education or not. Each interview lasted between 45 and 60 minutes.

\section{Trustworthiness}

Four criteria [10] for enhancing rigor in qualitative research (credibility, confirmability, dependability, and transferability) were used to ensure trustworthiness of the results. The qualitative data were validated to ensure confirmability [8]. Credibility was guaranteed by using the member checking approach in which the researchers referred back to 7 selected participants to verify the data and interpretation of the findings. Confirmability was ensured through the process of bracketing where by all previous knowledge, beliefs and common understanding about stigma and discrimination towards PLWHA were set aside. Dependability was ensured through the review of the results by an independent person. Transferability was established through collection of data that included field notes, together with a rich mix of participants' narrations.

\section{Data Analysis}

Data were analysed using ATLAS. ti version 5 [9]. The interviews were transcribed verbatim. The transcribed data from each interview were read and key words and significant statements were selected and reviewed. Words with similar meanings were placed into categories of major themes and sub themes. Code directorate was used to check whether the definitions of the codes were true and valid. Code directorate also helped to interpret the findings by attaching meaning and significance to the analysis. The emerging theme and sub themes are reported as results of the study.

\section{Results}

\subsection{Demographic Characteristics of the Participants}

The demographic characteristics of the participants are summarized in Table 1. Most of the participants (8) were aged between 26 and 45 years, while 4 were aged between 20 and 25 years. There was one teenager and those aged between 46 and 60 years (2) were few (Table 1). There were more female (9) than male (6) participants. The majority of the participants were female housewives (6). There were 3 people that were engaged in small businesses (Table 1). Other 3 participants were employed while 2 were pensioners and only one did not have any occupation. Regarding literacy and numeracy, a total of 12 participants were literate and numerate. The marital status of the participants shows that 6 were married, while 2 were single and another 2 were divorced. There were 4 widows while only one participant was a widower (Table 1). 
Table 1. Summary of demographic characteristics for the participants.

\begin{tabular}{|c|c|}
\hline Demographic Characteristic & Number of participants \\
\hline Age group & (n) \\
\hline 13 to 19 (Teen age) & 1 \\
\hline 20 to 25 & 4 \\
\hline 26 to 45 & 8 \\
\hline 46 to 60 & 2 \\
\hline Sex of participants & (n) \\
\hline Male & 6 \\
\hline Female & 9 \\
\hline Occupation of participants & (n) \\
\hline Housewives & 6 \\
\hline Business & 3 \\
\hline Formal employment & 3 \\
\hline Pensioners & 2 \\
\hline No occupation & 1 \\
\hline Literacy level of the participants & (n) \\
\hline Literate and numerate & 12 \\
\hline Illiterate & 3 \\
\hline Marital status & (n) \\
\hline Married & 6 \\
\hline Single & 2 \\
\hline Divorced & 2 \\
\hline Widows & 4 \\
\hline Widowers & 1 \\
\hline
\end{tabular}

\subsection{Emerging Themes}

One major theme "stigma and discrimination” and four sub themes emerged from the participants' narrations. The sub themes were:

1) Experience of PLWHA on stigma and discrimination;

2) Perception of PLWHA on the reasons for being stigmatized;

3) Perception of PLWHA on the signs of stigma and discrimination;

4) Perception of PLWHA on the impact of stigma and discrimination on their quality of life.

\subsubsection{Experiences of PLWHA on Stigma and Discrimination}

Results show that the participants in the study were cared by a close family member in the form of their own children, brother or sister or a spouse. In addition all the participants narrated to have experienced some form of stigma and discrimination for being HIV positive. A 32-year-old female participant had this to share:

"Stigma and discrimination is the biggest problem that we face in the villages. When people discover that you are HIV positive, they avoid you and shun from you. Sometimes even when you call them they reply saying that they are not around... they have gone away... when in actual fact, they are available but they just do not want to be associated with you anymore".

Narrations from some of the participants indicated that they were aware that living with HIV and AIDS was not the end of life and therefore they were not worried even when they were being stigmatized and discriminated against. A 40-year-old male participant had this to share:

"Madam, as long as HIV and AIDS are there, stigma will always be there too. Who wants to get HIV today? Nobody. So I don't blame them, let them discriminate me and one day they will understand when they have a member in their family with HIV. I did not invite HIV myself. I got it from my husband and where he got it, I 
don't know either".

Another 48-year-old female participant lamented that it was normal to live with HIV and AIDS and therefore, it was also normal to be stigmatized and discriminated against.

"It is normal to be discriminated and I don't get worried because even some people who do not have HIV are also discriminated especially those who are poor and what more with me? Until the time when everybody will understand what HIV is, then we shall be one. I am happy that my volunteer does not discriminate me instead she is discriminated because she is associated with CHBC services".

Most of the participants cited distant relatives (especially those from the extended family relationship), friends and church members as the ones who stigmatized them most. However, participants' narrations suggest that close family members who were the main care givers did not stigmatize or discriminate against the participants.

"My relatives stigmatize me, especially those from a distant relationship. They do not give me any assistance. When they see members of the CHBC team coming to my house, they take advantage and laugh at me for having HIV and AIDS”. A 19-year-old female participant narrated.

Results show that gossip was also another challenge. In addition to the distant relations, friends and church members were also at the centre of gossip towards the PLWHA. A 35-year-old female participant narrated her experience as follows:

"The biggest source of stigma and discrimination is unfortunately our own distant relatives and they are the same people that are expected to provide care to us. As a result, the home based care burdens only the close family members such as spouses and children. Gossip is also another challenge, the distant relatives, friends and even fellow church members gossip a lot”.

The stigma and discrimination from friends and church members was a source of frustration by the participants as narrated by a 50-year-old male participant.

"I am discriminated against by a lot of friends even fellow church members. They do not show it openly, but I know through their actions that they are discriminating against me. For example, sometimes when we are in a group, and we want to form smaller groups, some people are not willing to be in the same group with me and let alone to sit near me".

A 58-year-old female participant also narrated her experience on being stigmatized and discriminated by her Church members, she explained that:

"Some church members that I used to chat with before I got sick do not come to visit me anymore. For example, when prayers are taking place at my house, some members do not come. What does that mean? And what are they afraid of, they are not away but they don't come. I know that they are afraid because they think that they might contract HIV from me".

\subsubsection{Perception of PLWHA on Reasons for Being Stigmatized}

The participants' narrations suggest that they felt they were stigmatized and discriminated against because HIV and AIDS is a life-threatening disease and nobody would want to associate with a life threatening condition. A 40-year-old male participant explained as follows. "HIV is a killer, who would want to associate with HIV positive people? Nobody can willingly accept to acquire HIV so it is not wrong to avoid us".

Another group of participants stated that HIV infection is associated with behaviours such as prostitution or promiscuity and therefore people felt that HIV and AIDS patients deserve shame. HIV infection is therefore often thought to be the result of personal irresponsibility. This point as shared by a 40-year-old female participant as follows:

"HIV infection is associated with behaviours such as prostitution or promiscuity, homosexuality and drug addiction. People think if you have HIV and AIDS you are an outcast and hence deserve shame”.

The perception that PLWHA deserve punishment was also raised by a 38-year-old male participant who narrated that: "Religious or moral beliefs lead some people to believe that being infected with HIV is the result of moral fault such as promiscuity or deviant sex behaviour that deserves punishment”.

The participants' narrations confirmed that some participants experienced stigma and discrimination as a form of punishment. A female teenager reported that her father was using stigma and discrimination to punish her for running away from home and getting married to a man he never approved. She narrated her experience as follows:

“My father doesn't want to see me and he doesn't want me to be part of the family because I misbehaved earlier by running away from the family to get married to a certain man. When he learnt that I was HIV positive, he 
made sure that he does not get concerned anymore".

Some participants indicated that most people do not know about how HIV is transmitted and they fear contracting it through contacts or close association with the PLWHA. A 26-year-old female participant narrated her experience as follows: "There is a lot of inaccurate information about HIV and AIDS on how it is transmitted. People are afraid of contracting the disease, therefore, HIV and AIDS patients are stigmatized and discriminated".

Participants in the study were able to identify that some relatives, friends and communities were failing to cope and therefore did not accept to live with PLWHA in their homes because they were afraid of contracting the virus. One participant narrated her experience like this: "Health care workers tried to explain to my distant family members on the importance of accepting me but they refused and do not seem to understand. I am happy that the health workers and my volunteer do not discriminate against me".

Most participants explained that they felt their distant family care givers were discriminating against because they had little knowledge of HIV and AIDS in general. They therefore indicated a need for community members to be given adequate information regarding HIV and AIDS so that they give proper care to their HIV and AIDS patients.

\subsubsection{Perception of PLWHA on Signs that Indicated Stigma and Discrimination}

All the participants explained that they suspected that people were stigmatizing and discriminating against them because most of their friends and distant relatives stopped visiting their homes. A 52-year-old male participant shared:

"You know madam; I am a victim of stigma and discrimination in this village. Even some of my distant relatives and friends stopped coming to my house long time ago when they discovered that I was HIV positive".

Some of the participants' narrations indicated that if friends and relatives came to visit them, then they opted to stay very far from them to avoid contracting the HIV as was narrated by a 32-year-old female participant: "It pains me when I see my friends not wanting to stay close to me for long period of time as we used to do in the past. I know some of my friends are still friendly to me but there are some who have changed tremendously".

Stigma and discrimination from friends are threatening. Some participants' narrations indicated that they noticed that some friends shunned away from them and in the process they lost best friends. A 28-year-old female participant narrated that: "Stigma and discrimination is the major concern to us the PLWHA. You notice that you have lost friends immediately they know about your positive HIV status. Even some of the best friends start shunning away from you with no proper reason".

Similar sentiments were shared by a 50-year-old male participant who also said: "The other sign is that sometimes, you greet them when they are passing by but they do not answer you. I do not know why, but may be one day I will know the answers. I am just worried about my children because they are still young. What will happen to them when I die? Who will take care of them in view of this discrimination?”

\subsubsection{Perception of PLWHA on the Impact of Stigma and Discrimination towards Their Quality of Life}

Results show that some individuals stigmatized patients because they were not aware of the consequences of the practice. The PLWHA explained that stigma and discrimination can make people reluctant to access HIV testing, treatment and care and therefore it must be discouraged among the community members. The majority of the participants pointed out that the close relatives of PLWHA that portrayed good attitude to their patients in return gave encouragement and hope to the patients. The narrations of participants also suggested that care givers who were close family members did not show any negative attitudes towards them. However, as the illness progressed, the community members and distant relations, developed negative attitudes towards the PLWHA and started to stigmatize and discriminate against them as was narrated by a 58 -year-old male participant:

"I have problems with the attitude of my distant relations and other community members which keep on deteriorating every day. I think they are tired of me and my illness and therefore most of the times they are discriminating against me. I have lost trust in them and whenever I see them, I feel sicker than before".

A 36-year-old female participant affirmed that absence of discrimination from close relatives made her feel good and encouraged. "This good behaviour from my relatives gives me courage and some hope for better life. I am encouraged that I am not different from any other person because of my HIV positive status. I live a happy life. The pain that is in me is always lessened because they always comfort and encourage me. With the ARVs 
that I am able to receive, nowadays I have very good life".

Similar sentiments were made by a 40-year-old male participant: "They are good to me. I have hope for the future. Yes, they love me and I want to live longer because they are not bothered with my sickness. When they are happy, I am also more than happy and I can move up and down with happiness. I know this means that my life is improving".

On the other hand, other participants affirmed the view that stigma and discrimination towards them caused loss of hope, giving up life quickly and therefore leading to experience of poor quality of life. An 18-year-old female participant explained this: "Stigma and discrimination make me feel miserable and sometimes I wish I could die early because I know I am bothering innocent lives. Sometimes I don't want to eat and I know my health is going down slowly".

Some participants felt that when people were discriminating against them it meant they were too ill and were about to die: "It makes the patient feel bad because you think you are very ill and therefore your condition goes down. In my case in such situations, I don't want to eat. I feel I am a burden to the people and it is better if I die to relieve them. Sometimes it reminds me of my late husband, and I think of the same situation happening to my children when I die. Then I cry internally the whole day with no comfort".

\section{Discussion}

In this study, most of the participants were aged between 26 and 45 years. These results agree with the 2010 Malawi Demographic Health Survey which reported that HIV prevalence increases with age for both men and women [2]. The results also show that most of the participants were women which further agree with the 2010 Malawi Demographic Health Survey that in Malawi, women are at the greatest risk of contracting HIV than men of the same age group [2].

The results that almost all the participants in the study faced some form of stigma and discrimination show a need for community sensitization on HIV and AIDS. Results show that stigma and discrimination should not be ignored or overlooked in the care of HIV and AIDS patients. In Malawi, like in many other African countries the high prevalence rate of HIV has necessitated the introduction of home based care where high level of support comes from close family members [3]. Family support is associated with better adjustment and coping treatment adherence during home based care of PLWHA [11].

In most cases, HIV-related stigma and discrimination severely hamper efforts to effectively fight the HIV and AIDS epidemic. Stigma remains the single most important barrier to public action. It is a main reason why too many people are afraid to see a doctor to determine whether they have the disease, or to seek treatment if they are HIV positive. It makes AIDS the silent killer, because people fear the social disgrace of speaking about it, or easily taking the available precautions. Stigma is a chief reason why the AIDS epidemic continues to devastate societies around the world [7].

Similar findings were reported by the Pan American Health Organization (PAHO) that stigma and discrimination threaten the quality of patient care as well as efforts to control the epidemic's spread [12]. WHO also cites fear of stigma and discrimination as the main reason why people are reluctant to be tested, to disclose HIV status or to take antiretroviral drugs. These factors all contribute to the expansion of the epidemic and a higher number of AIDS related deaths. Unwillingness to take an HIV test means that more people are diagnosed late, when the virus has already progressed to AIDS, making treatment less effective and causing early death [7].

Results of this study show that although HIV and AIDS have been around for a decade now, there are still misconceptions which have contributed to a lot of mixed reactions from people. The fear surrounding the emerging epidemic in the 1980s is still fresh in many people's minds. At that time very little was known about the transmissibility of the virus, which made people become scared of those infected due to fear of contagion which was the same experience with participants of this study [7].

According to a study which was done in Tanzania, it was found that PLWHA expressed concern that attitudes and misconceptions on HIV and AIDS have a great impact on the overall well being of HIV and AIDS patients [13]. Therefore, providers who have negative attitudes and misconceptions towards HIV and AIDS will not provide good quality care to the patients therefore affecting patient's quality of life.

Other studies have reported that PLWHA preferred to be cared by their volunteers [13]. However in this study, the volunteers visited PLWHA at regular intervals but the main care givers on daily basis were the close relatives. Thus, providers are able to relate to service users and offer peer support which may make the infected in- 
dividuals feel comfortable.

Regarding stigma against the PLWHA, Nettleton [14] observed that stigma is not easy to fight because of its social construction. He further argued that while medicine has its own meaning of the body in relation to illness and health as reflected in the signs and symptoms, individuals have their own social meanings for the HIV and AIDS signs and symptoms and these differences may pose difficulties in curbing stigma [14].

In this study the sources of stigma and discrimination for most of the participants were relatives, friends and church members. In Malawi, there is clear evidence that families especially close relatives such as children, siblings and spouses play an important role in providing support and care for PLWHA [15]. The fact that there were some responses from participants indicating discrimination by church members implies that churches were also a source of stigma to HIV and AIDS patients. This is not desirable because religion has always been part of social life in most of the countries including Malawi. However, religion has also always been an important form of social control especially in the areas of sexuality. It provides important ethical guidelines for living, for interpreting natural events including disasters and misfortune, and for coping with life's milestones, from birth through illness to death [7]. Results show that HIV and AIDS pose new challenges to religion. The fact that its main mode of transmission is sexual, HIV and AIDS intensifies the tensions that are present around sexuality. Many religious groups have had ambivalent attitudes towards sexuality [7]. The epidemic is interpreted by some people as divine punishment for sexual transgressions from premarital sex to homosexuality. The stigma posed by religion can thus be powerful. People often avoid working with or supporting HIV and AIDS people because they are seen as sinners who deserve to become infected. Religious prejudices, mixed with misconceptions about HIV and AIDS, become a dangerous and volatile mixture that sends many people to their deaths [7].

Contrary to findings of this study, at a certain HIV and AIDS conference in 1990, Bishops of Southern Africa explained that "perhaps the AIDS crisis is God's way of challenging us to care for one another, to support the dying and to appreciate the gift of life. AIDS need not be merely a crisis: It could also be a God given opportunity for moral and spiritual growth, a time to review our assumption about sin and morality and that the modern epidemic of AIDS calls for a pastoral response" [16].

This message of discouraging stigma and discrimination was also supported at the Bishops' Conference of the Philippines in 1993 where it was stated that "for us, an encounter with people infected with HIV and AIDS should be a moment of grace and opportunity for us to be Christ's compassionate presence to them as well as to experience His presence in them" [16].

AIDS related stigma refers to the prejudice and discrimination directed at PLWHA and the groups and communities that they are associated with [7]. In this study, PLWHA were being rejected by some members of their community, shunned, discriminated against and even became centres of gossip. Results also showed that the main reasons for discrimination was fear of contracting HIV and this was because some relatives and community members had little knowledge on HIV and AIDS transmission.

Providing services for PLWHA is a rewarding experience, but it is stressful, leading to depression and frustration especially when the care givers and the community are not given adequate information. In this study, lack of knowledge by some community members and relatives affected the quality of care for the participants as shown by the participants' narration that most of the people stigmatized and, shunned them, and distanced themselves because they lacked information on HIV and AIDS. In Malawi, knowledge about HIV and AIDS among communities is high, but the people do not provide quality home based care because of fear and misconceptions about the disease [15]. In addition, limited knowledge on home based management of PLWHA created fear among the home based carers [15]. Consequently, the PLWHA are shunned by friends and other community members. These results are supported by a study in Botswana [17] where families that received detailed information about the condition of patients manifested more vigilant coping skills compared with families that had little information.

A continuum of care for persons with chronic illnesses is provided through CHBC when the patients are discharged from the health facilities and go home. It also gives hope through quality and appropriate care that helps family caregivers and sick members to maintain their independence and achieve the best possible quality of life [18]. It is an established component of the continuum of care and support advocated by WHO and UNAIDS and planned by many African countries including Malawi [19] [20]. According to a study by Mohammad and Gikonyo [21], CHBC is an example of the community-driven initiatives which focus on HIV and AIDS care and treatment activities. 


\section{Conclusion}

Participants in this study faced stigma and discrimination which made it difficult for them to cope with their illness. Although close relatives were the main care givers, distant relatives, friends and church members were main people that stigmatized and discriminated against the PLWHA. Most of the PLWHA were aware that the major reason that made people stigmatize and discriminate against them was limited knowledge on the mode of HIV and AIDS transmission. Stigma and discrimination was evident to most PLWHA when suddenly they lost their best friends when they knew the HIV positive status of the PLWHA. Stigma and discrimination made the PLWHA think that their health was deteriorating and develope negative attitude towards their treatment. Consequently, stigma and discrimination made the PLWHA reluctant to access treatment and care thereby adversely affecting their quality of life. There is therefore a need to create community awareness about HIV and AIDS and the proper care of PLWHA in the CHBC groups in Malawi.

\section{Recommendations}

Some individuals stigmatized patients because they were not aware of the consequences of the practice. It is therefore recommended that the Ministry of Health and its partners make an effort to continue sensitizing the general public on various issues of HIV and AIDS including effects of stigma and discrimination on PLWHA. Considering that even church members stigmatize and discriminate against HIV and AIDS patients, it is recommended that an effort be made to involve faith based organizations in HIV and AIDS awareness campaigns. An effort should also be made to deliberately sensitize people on the effects of stigma and discrimination. Stigma and discrimination are barriers to effective prevention of HIV and AIDS, therefore the public should be reminded that practicing stigma and discrimination against PLWHA is a violation of their human rights.

\section{Study Limitation}

The study participants were drawn from urban and peri-urban areas of Lilongwe district and like in any qualitative study, the results may not be generalized to portray the perception of PLWHA on stigma and discrimination in Malawi, although the trend is similar.

\section{Conflict of Interest}

None of the authors had any conflict of interest in the manuscripts being published in the World Journal of AIDS.

\section{Acknowledgements}

This study was funded by the University of Malawi through Kamuzu College of Nursing as part of Ph.D. studies for the senior author.

\section{References}

[1] UNAIDS (2008) Epidemiological Fact Sheet on HIV and AIDS. Core Data on Epidemiology and Response. Accessed: 1 April 2010. http://www.who.int/globalatlas/predefinedReports/EF2008_MWpdf

[2] National Statistical Office (NSO) and ICF Macro (2011) Malawi Demographic and Health Survey 2010. Zomba, Malawi, and Calverton, Maryland, USA: NSO and ICF Macro.

[3] Pindani, M., Maluwa, A., Nkondo, M., Nyasulu, B.M. and Chilemba, W. (2014) Perception of People Living with HIV and AIDS Regarding Home Based Care in Malawi. Journal of AIDS \& Clinical Research, 4, 201. http://dx.doi.org/10.4172/2155-6113.1000201

[4] Stanhope, M. and Lancaster, J. (2004) Community and Public Health Nursing. 6th Edition, Mosby, St. Luis.

[5] Kamphinda, S. (2004) Lives Experiences of Children from Families with HIV and AIDS Home Based Care Patients in Lilongwe City North. M.Sc. Thesis, University of Malawi, Kamuzu College of Nursing, Lilongwe.

[6] The Global Coalition on Women and AIDS (2008) Support Women Caregivers: Fight AIDS. Published on line. http://womenandaids.unaids.org

[7] AVERT (2008) Stigma, Discrimination and Attitudes to HIV and AIDS. Published on line. http://www.avert.org/aidsstigma.htm 
[8] Polit, D.F. and Beck, C.T. (2008) Nursing Research: Generating \& Assessing Evidence for Nursing Practice. 8th Edition, Lippincott Williams \& Wilkins, Philadelphia.

[9] Straubert, H.J. and Carpenter, D.R. (1995) Qualitative Research in Nursing: Advancing the Humanistic Imperative. Lippincott, Philadelphia, 326 p.

[10] ATLAS. ti. Manual (2004) The Knowledge Workbench: User’s Guide and Reference. Visual Qualitative Data Analysis \& Knowledge Management in Education, Business, Administration \& Research. 2nd Edition, Scientific Software, Berlin.

[11] Miller, I., Bishop, D. and Stain, M. (2007) Relationship Quality among HIV Patients and Their Caregivers. AIDS Care, 19, 203-211. http://dx.doi.org/10.1080/09540120600624278

[12] Pan American Health Organization (2008) HIV Patients Face Stigma in Region’s Health Sector. New PAHO Report Released on World AIDS Day. Published on line. http://www.paho.org/English/DD/PIN/ptoday01_mar04.htm

[13] (2008) Home Based Care Services in Tanzania. The United Republic of Tanzania, The Prime Minister's Office, Tanzania Commission for AIDS. Published on line. http://www.tacaids.go.tz

[14] Nettleon, S. (2006) The Sociology of Health and Illness. Polity press. http://www.amazon.co.uk/Sociology-Health-Illness-Sarah-Nettleton/dp/0745628281

[15] Nkhandwe, F.F. (2001) Knowledge and Attitudes of the Family Members towards HIV/AIDS Home Based Care in 22 Villages of Ekwendeni Hospital Catchment Area, Malawi. M.Sc. Thesis, University of Malawi, Kamuzu College of Nursing, Lilongwe.

[16] Religious Leaders Speak Out on HIV and AIDS at a Conference (2000) The International Newsletter on HIV/AIDS Prevention and Care. AIDS Action, 47, 1-7.

[17] Ndaba-Mbata, R. and Seloiwe, E. (2000) Home Based of Terminally Ill in Botswana: Knowledge and Perceptions. International Council of Nurses, International Nursing Review, 47, 218-223. http://dx.doi.org/10.1046/j.1466-7657.2000.00023.x

[18] HOPE for AIDS (2008) Community Care in Malawi. Published on line. http://hopeforaids.org/story.asp?id=91

[19] WHO/UNAIDS (2000) Draft Working Document: Key Elements in HIV/AIDS Care and Support. Geneva.

[20] Ministry of Health (2000) Malawi Community Home Based Care Policy and Guidelines. Lilongwe, Malawi.

[21] Mohammad, N. and Gikonyo, J. (2005) Operational Challenges Community Home Based Care (CHBC) for PLWHA in Multi-Country HIV/AIDS Programs (MAP) for Sub-Saharan Africa. African Region Working Paper Series No. 88. 